\title{
Design of Sierpinski Carpet Fractal Antenna using Artificial Neural Networks
}

\author{
Jagtar Singh Sivia \\ Associate Professor \\ Yadavindra College of \\ Engineering Talwandi Sabo
}

\author{
Amarpartap Singh \\ Professor ECE Department \\ Sant Longowal Institute of \\ Engineering Longowal
}

\author{
Tara Singh Kamal \\ Professor ECE Department \\ Radient College of Engineering \\ Abohar
}

\begin{abstract}
This paper deals with utilization of artificial neural networks for the design of Sierpinski carpet fractal antenna. The difficulty in designing of fractal microstrip patch antennas is due to the involvement of large number of physical parameters and hence their associated optimal values. It is indeed very difficult to formulate an exact numerical solution through empirical studies based on practical observations. In order to circumvent this problem, an alternative solution is achieved using artificial neural networks. The proposed technique used feed-forward back-propagation artificial neural network (FFBP-ANN) with one hidden layer to approximate neural model of this antenna. Sierpinski carpet fractal antenna is simulated using IE3D software. The investigation is done between the ranges of frequencies from 1 to 20Ghzs. The results obtained by using artificial neural networks are in agreement with simulated results.
\end{abstract}

\section{Keywords}

Fractal, Carpet, Artificial Neural Networks, Sierpinski, Antenna.

\section{INTRODUCTION}

Microstrip antenna has attracted wide interest due to important characteristics such as light weight, low profile, low cost, mechanically robust, simple to manufacture and easy to be integrated with RF devices [1].Today fractal antennas have been well known for their multi-band characteristics. A fractal is a rough or fragmented geometric shape that can be subdivided in parts, each of which is a reduced-size copy of the whole. Fractals are generally self-similar and independent of scale. It is an antenna that uses a fractal design to maximize the length, or increase the perimeter (on inside sections or the outer structure), of material that can receive or transmit electromagnetic waves within a given total surface area or volume [2]. Fractal is a figure that "looks" the same independent of size scaling, we come upon the amazing realization that a fractal shaped metal element can be used as an antenna over a very large band of frequencies. Fractal geometry is also combined with electromagnetic theory for the purpose of investigating a new class of radiation, propagation, and scattering problems, one such area is fractal electrodynamics [3-4]. There are many mathematical structures that are fractals; e.g. Sierpinski's gasket, Cantor's comb, von Koch's snowflake, the Mandelbrot set, the Lorenz attractor, et al. In this paper the concept of fractal has been applied to the geometry of square microstrip patch antenna to obtain multi-band frequency operation. Fractal antenna has various features such as it can operate as wideband/multi-band antenna, compact size, frequency independent antenna and it has a feature of fractal loading which adds inductance and capacitance. Artificial neural networks are one of the popular intelligent techniques in solving engineering problems. Neural processing presents a different way to store and manipulate knowledge. It uses a connectionist approach, where connections emphasize the learning capability and discovery of representations. An artificial neural network (ANN) is a system that is built in accordance with the human brain [5]. An ANN consists of a few types of many, simple, nonlinear functional blocks, which are called neurons. Neurons are organized into layers, which are mutually connected by highly parallel synaptic weights. The ANN exhibits a learning ability, synaptic weights can be strengthened or weakened during the learning process and in this way, information can be stored in the neural network [6-7], In ANN model no formula is necessary to design microstrip antenna due to its empirical nature, based on the observation of physical phenomenon. Neural networks have been widely used in electronics since middle eighteens. In area of microwave applications, neural networks has been used to design rectangular microstrip antenna [8-11].Also ANN can be used to calculate different parameters of rectangular microstrip antenna such as radiation efficiency [12], resonant frequencies of triangular and rectangular microstrip antennas [13], resonant resistance calculation of electrically thin and thick rectangular microstrip antennas [14], input impedance of rectangular microstrip antennas [15].Similarly artificial neural networks have been used for the design of circular antenna [16] , calculating different parameters such as resonant frequency [17] and input impedance [18] of circular microstrip antenna .In this paper an artificial neural network has been used for the design of a Sierpinski carpet fractal antenna. The Sierpinski carpet is constructed using square geometries.Fig. 1 shows the process of iteration for Sierpinski carpet fractal antenna. The iteration for this process is up to third iteration.

\section{DESIGN OF ANTENNA}

Design of microstrip antenna includes the specified information of dielectric constant of substrate $\left(\varepsilon_{\mathrm{r}}\right)$, the resonant frequency $\left(f_{r}\right)$ and height of substrate $(h)$. For an efficient radiator, practical width that leads to good radiation efficiencies as given in [11] is given by

$$
W=\frac{1}{2 f_{r} \sqrt{\mu_{0} \varepsilon_{0}}} \sqrt{\frac{2}{\varepsilon_{r}+1}}=\frac{v_{0}}{2 f_{r}} \sqrt{\frac{2}{\varepsilon_{r}+1}}
$$

Where, $\mathrm{V}_{0}$ is free-space velocity of light.

The effective dielectric constant of micro-strip antenna as given in [11]

$$
\varepsilon_{e f f}=\frac{\varepsilon_{r}+1}{2}+\frac{\varepsilon_{r}-1}{2}\left[1+12 \frac{h}{W}\right]^{-\frac{1}{2}}
$$


Once $\mathrm{W}$ is found using equation (1), determine the extension of length

$$
\Delta L=h \frac{\left(\varepsilon_{\text {reff }}+0.3\right)\left(\frac{W}{h}+0.264\right)}{\left(\varepsilon_{\text {reff }}-0.258\right)\left[\frac{W}{h}+0.8\right]}
$$

Then actual length of patch as given in [11]

$$
L=\frac{1}{2 f_{r} \sqrt{\varepsilon_{\text {reff }}} \sqrt{\mu_{0} \varepsilon_{0}}}-2 \Delta L
$$

In this paper for designing Sierpinski carpet fractal antenna the operating frequency is taken $2.0 \mathrm{GHz}$, Height of substrate $\mathrm{h}=1.588 \mathrm{~mm}$, dielectric constant $\varepsilon_{\mathrm{r}}=2.2$. So Initial Length $=50$ $\mathrm{mm}$ and breadth $=50 \mathrm{~mm}$ of micro strip patch antenna can be calculated using equations (1), (2), (3) and (4) .Then rectangular microstrip antenna with dimensions $\mathrm{L}=\mathrm{W}=50 \mathrm{~mm}$, $\mathrm{h}=1.588 \mathrm{~mm}$ and $\varepsilon_{\mathrm{r}}=2.2$ is simulated using IE3D software as shown in Fig.2. This iteration of antenna is known as zero iteration of Sierpinski carpet fractal antenna. Return loss versus frequency plot of this antenna for $\mathrm{L}=\mathrm{W}=50$, height of substrate $\mathrm{h}=1.588 \mathrm{~mm}$ and dielectric constant $\varepsilon \mathrm{r}=2.2$ is shown in fig.5.

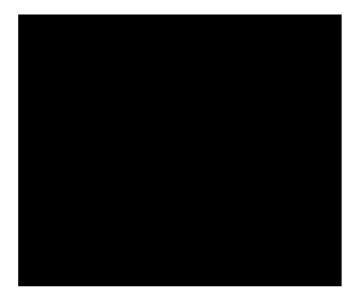

Stage 0

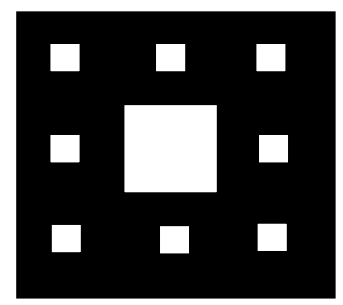

Stage 2

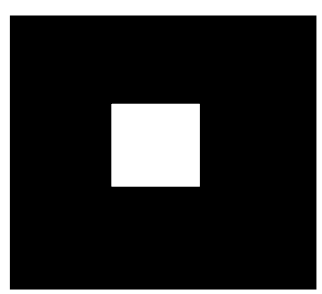

Stage 1

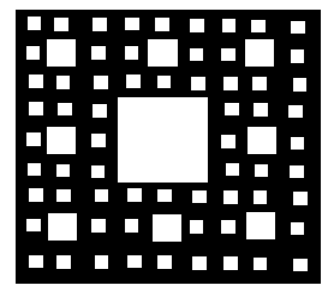

Stage 3
Fig 1: Sierpinski carpet fractal antenna up to third iteration

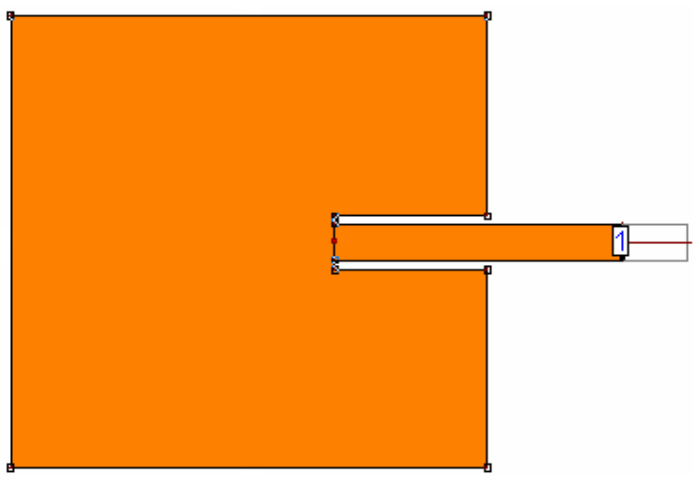

Fig 2: Simulated structure Sierpinski carpet fractal antenna for 0 iteration using IE3D

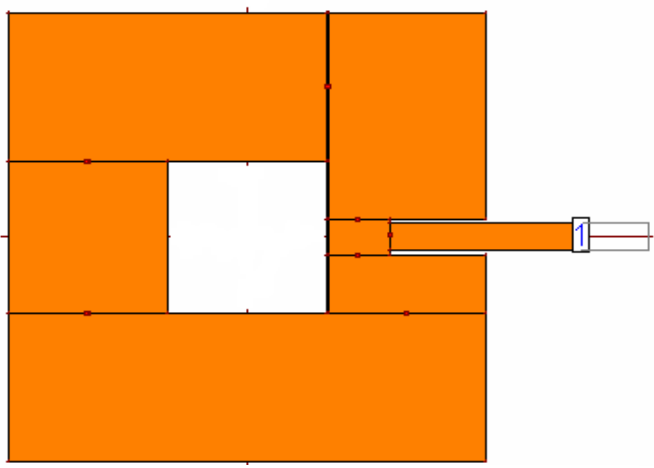

Fig 3: Simulated structure Sierpinski carpet fractal antenna for $1^{\text {nd }}$ iteration using IE3D

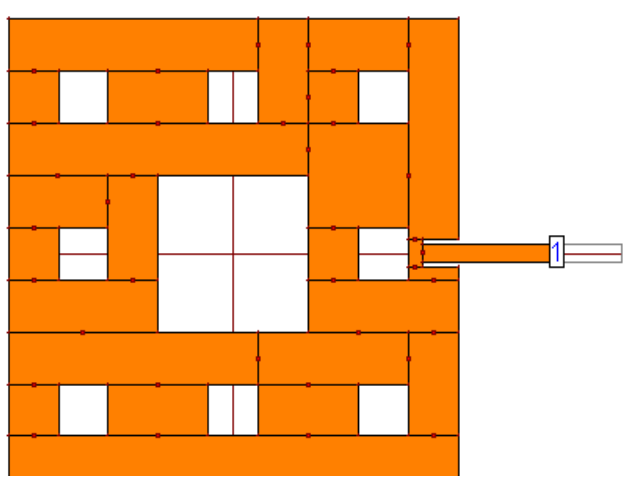

Fig4: Simulated structure Sierpinski carpet fractal antenna for $2^{\text {nd }}$ iteration using IE3D Software

So for resonant frequency $=1.99721, \mathrm{~h}=1.588 \mathrm{~mm}, \varepsilon \mathrm{r}=2.2$ and $\mathrm{n}=0$ side length of rectangular microstrip antenna is $50 \mathrm{~mm}$. Then a square with $16.666 \mathrm{mmX} 16.666 \mathrm{~mm}$ is dropped to get ist iteration geometry as shown in fig.3.Then from ist iteration eight squares $5.555 \mathrm{mmX} 5.555 \mathrm{~mm}$ with coordinates as centre $(16.666,0),(16.666,16.666),(0,16.666),(-16.666$, $16.666),(-16.666,0),(-16.666,-16.666),(0,-16.666)$ and (16.666,- 16.666)are dropped for getting $2^{\text {nd }}$ iteration geometry of Sierpinski carpet fractal antenna as shown in fig.4.Return loss versus frequency plot of Sierpinski carpet fractal antenna for $\mathrm{L}=\mathrm{W}=50$, height of substrate $\mathrm{h}=1.588 \mathrm{~mm}$, dielectric constant $\varepsilon_{\mathrm{r}}=2.2$ for $1^{\text {st }}$ iteration and $2^{\text {nd }}$ iteration are 


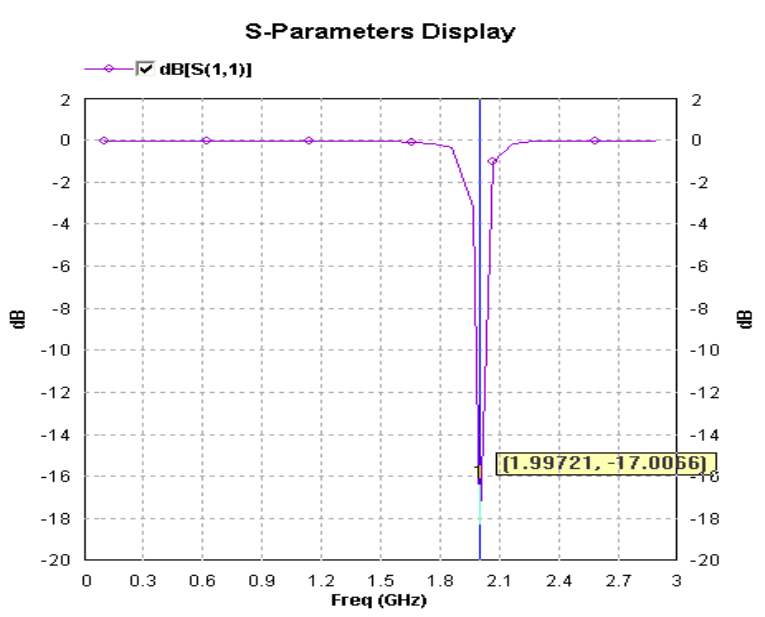

Fig5: Return loss versus frequency plot of fractal antenna for 0 iteration

shown in fig. 6 \& fig. 7 respectively. For $2^{\text {nd }}$ iteration from the plot as shown in fig.7. it is clear that this antenna can operate at four frequencies $4.1823 \mathrm{GHz}, 5.987 \mathrm{GHz}, 13.5876 \mathrm{GHz}$ and 16.2436Ghz as the return losses are less than $-10 \mathrm{db}$ at these frequencies. So for resonant frequencies 4.1823 $\mathrm{GHz}, 5.987 \mathrm{GHz}, 13.5876 \mathrm{GHz} \quad, 16.2436 \mathrm{Ghz}, \quad \mathrm{h}=1.588 \mathrm{~mm}$ ,$\varepsilon_{\mathrm{r}}=2.2$ and $\mathrm{n}=2$ the side length of Sierpinski carpet fractal antenna is $50 \mathrm{~mm}$.In this way a set of 97 input-output pair generated for training and a set of 165 pars generated for validation of neural network.

\section{DESIGN OF SIERPINSKI CARPET ANTENNA USING FFBP-ANN:}

For design of Sierpinski Carpet Fractal antenna using ANN one should have information of resonant frequency $\left(f_{r}\right)$ of microstrip antenna, dielectric constant of substrate $\left(\varepsilon_{\mathrm{r}}\right)$, height of substrate (h) and no. of iterations (n) of microstrip antenna. Different values side lengths of this antenna are calculated for different values resonant frequency $\left(f_{r}\right)$ of microstrip antenna, dielectric constant of substrate $\left(\varepsilon_{\mathrm{r}}\right)$, height of substrate (h) and no. of iterations (n) of microstrip antenna, using IE3D software. Neural model for estimating the side length of Sierpinski carpet fractal antenna is shown in fig.8., which shows that proposed FFBP-ANN Model have four in-puts (resonant frequency ' $f_{\mathrm{r}}$ ', height of substrate ' $h$ ', dielectric constant of substrate ' $\varepsilon_{\mathrm{r}}$ ' and number of iterations ' $\mathrm{n}$ ' and single output L side length ).Neural network trained on data dictionary have been applied to calculate the side length of Sierpinski carpet fractal, i. e., L for given values of resonant frequency ' $\mathrm{f}_{\mathrm{r}}$ ', height of substrate ' $\mathrm{h}$ ', dielectric constant of substrate ' $\varepsilon$ ' and number of iterations ' $n$ ' . The implemented neural model comprised of one hidden layer of tansigmoidal neurons with activation function $\mathrm{f}_{1}$. The first layer receives input data and its output is given as input to output layer. The output from neurons of hidden layer is transmitted to the output layer of single linear neuron with activation function $\mathrm{f}_{2}$ which finally computes the network output. Output of the proposed ANN is computed by

$X=f_{2} \quad\left([O W] \quad\left(f_{1} \quad([F W][Y]+[F B])+[O B]\right)\right.$
$\mathrm{Y}=\left[\begin{array}{l}f_{i} \\ h_{i} \\ \varepsilon_{i} \\ n_{i}\end{array}\right]$

$\mathrm{X}=[\mathrm{L}]$

$\mathrm{FW}=\left[\begin{array}{cccc}f w_{11} & f w_{12} & f w_{13} & f w_{14} \\ f w_{21} & f w_{22} & f w_{23} & f w_{24} \\ . & . & . & .\end{array}\right]$

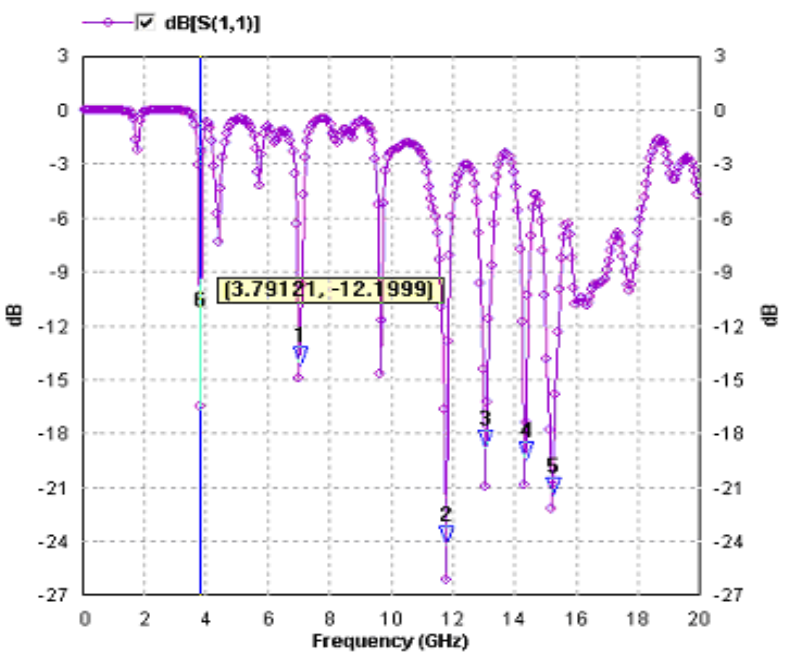

Fig.6: Return loss versus frequency plot of fractal antenna for 1st iteration

S-Parameters Display

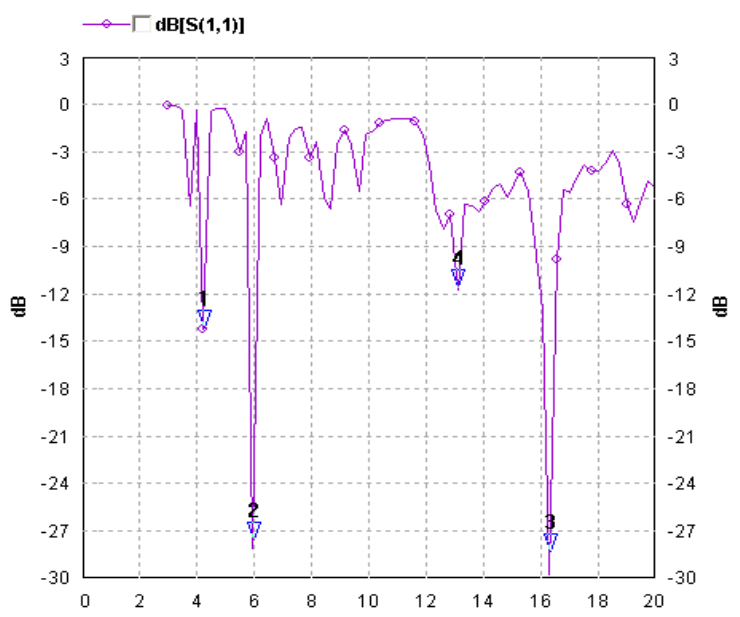

Fig.7: Return loss versus frequency plot of fractal antenna for 2nd iteration 
$[\mathrm{FB}]=\left[\begin{array}{c}f b_{1} \\ f b_{2} \\ \cdot \\ \cdot \\ \cdot \\ f b_{35}\end{array}\right]$,

$[\mathrm{OB}]=\left[\mathrm{ob}_{1}\right]$

\section{RESULTS AND DISCUSION:}

\subsection{Results of ANN Training}

In order to evaluate the performance of proposed MLFFBPANN based model for the design of Sierpinski carpet fractal, simulation results are obtained using IE3D software for accurate determination of dimensions of this antenna. Then ANN is trained with 97 input-output training patterns. This training data is used for training the proposed 4-35-1 ANN structure with Levenberg Marquardt algorithm and results in terms of performance parameters such as no. of epochs taken by each algorithm for training, performance goal Mean Square Error (MSE), maximum absolute value of absolute

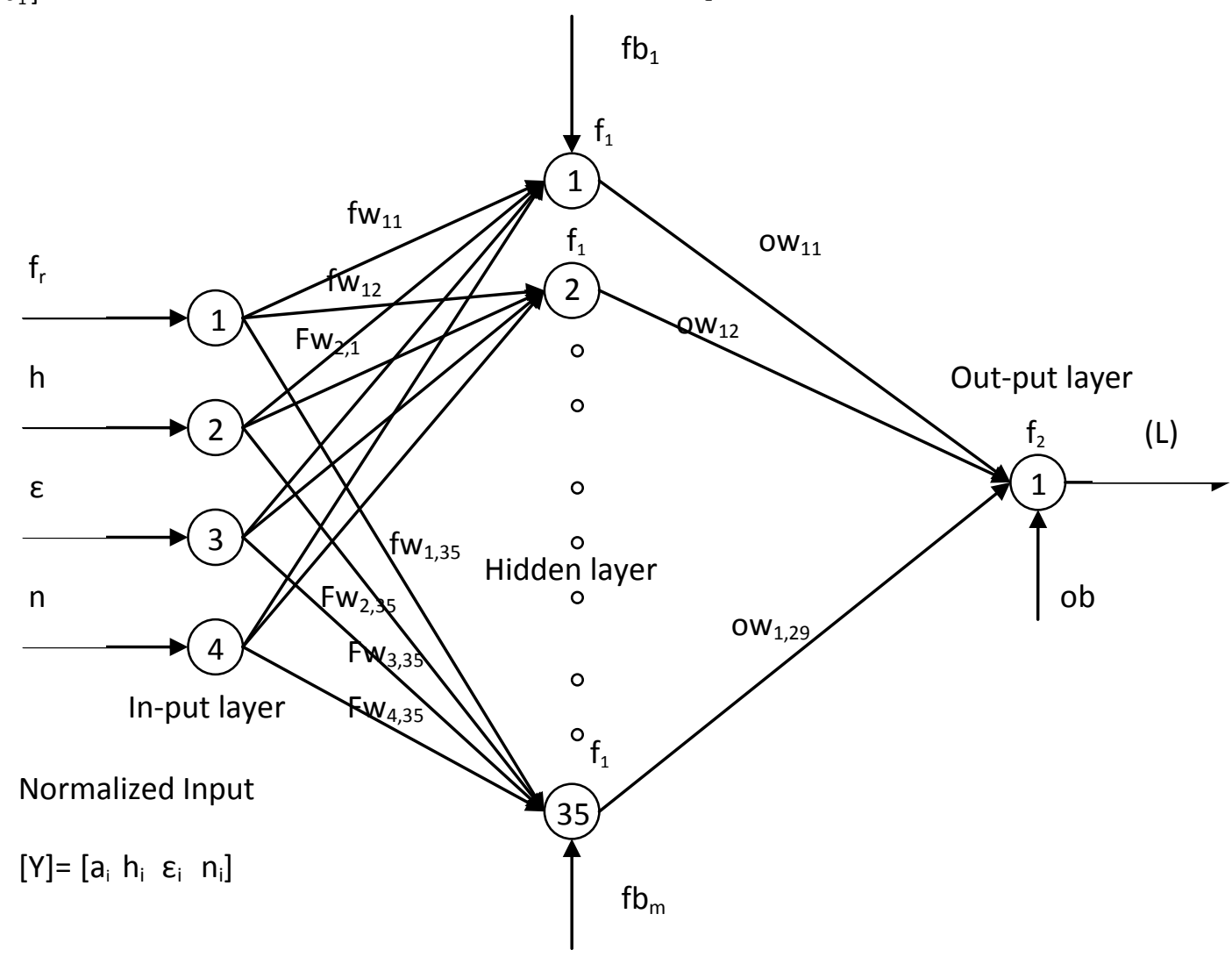

Fig.8: Proposed FFBP-ANN based model for design of Sierpinski carpet fractal antenna

$[\mathrm{OW}]=\left[\begin{array}{lllll}O W_{11} & O W_{12} & \cdot & . & O W_{1,35}\end{array}\right]$

MSE, i. e., performance index is given in [18].

$\mathrm{MSE}=\frac{1}{n} \sum_{i=1}^{n}\left[y_{i}-F_{A N N}\left(x_{i}\right)\right]^{2}$

The proposed model is trained with Levenberg Marquardt algorithm and structure 4-35-1 as shown in fig.8. is found best fit structure for estimation of side length of Sierpinski carpet fractal antenna. error and percentage error $(\% \mathrm{FS})$ are shown in Table-1. Mean Square Error $(\mathrm{MSE})=8.74 \mathrm{e}-007 / 1 \mathrm{e}-006$, learning rate $=0.05$ and maximum number of epochs $=177$. The learning characteristic of proposed MLFFBP-ANN based model trained with best Levenberg Marquardt training algorithm is shown in Fig.9. It has been observed that total no. of only 177 epochs are needed to reduce MSE level to a low value 8.74e007. Achievement of such a low value of performance goal (MSE) indicates that trained ANN model is an accurate model for estimating side length of Sierpinski carpet fractal antenna. The absolute error and error (\%FS) at each value of side length of Sierpinski carpet fractal antenna as result of training study with Levenberg-Marquard algorithm are shown in Fig.10. and 11. It is observed that maximum absolute value of absolute error between side length of Sierpinski carpet fractal antenna obtained by simulations and estimated by ANN is 
found to be only 0.0045152894159 and that of error $(\% \mathrm{FS})$ is 0.018060132958 summarized in Table-1.

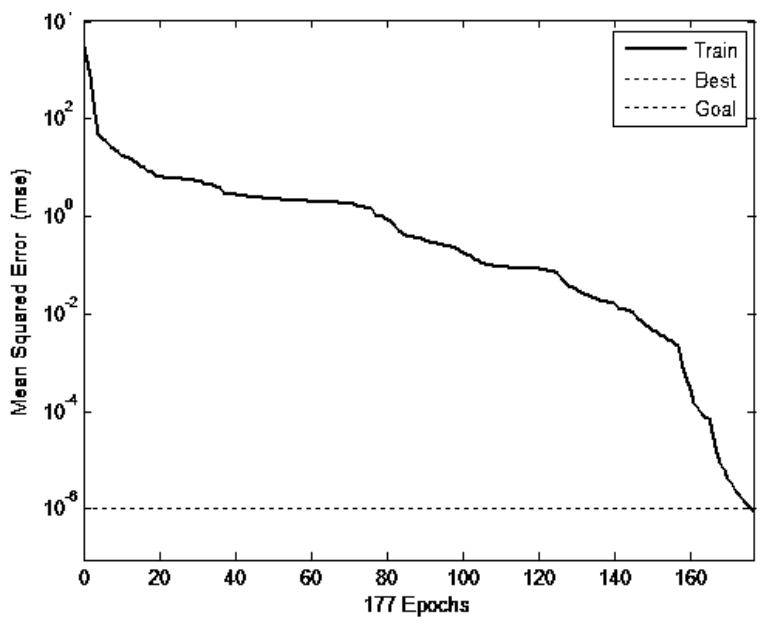

Fig.9: Learning Characteristics of the FFBP-ANN

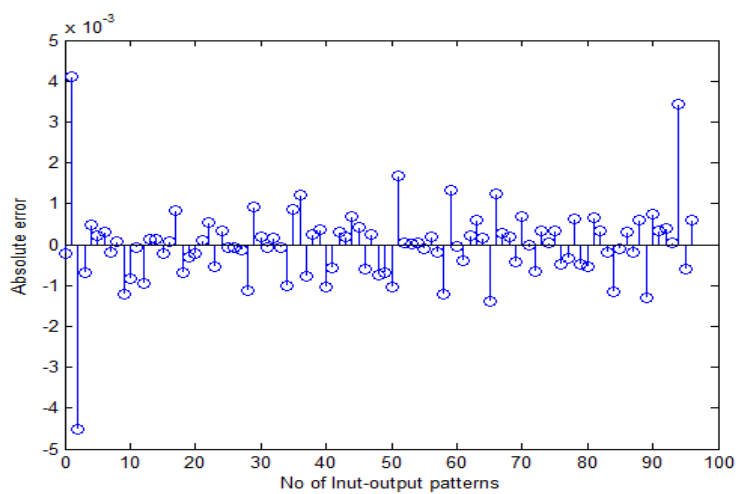

Fig.10: Absolute Error between values of the side length of Sierpinski carpet fractal antenna obtained by simulation and estimated using ANN model as a result of training study.

Table II. Comparison of error obtained for finding the side length of Sierpinski carpet fractal antenna using MLFFBP-ANN 4-35-1 structure for validation of data

\begin{tabular}{|c|c|c|}
\hline Parameter & $\begin{array}{c}\text { Maximum absolute error } \\
\text { (Absolute value) }\end{array}$ & $\begin{array}{c}\text { Maximum absolute } \\
\text { error(\%FS) } \\
\text { (Absolute value) }\end{array}$ \\
\hline $\begin{array}{c}\text { Side } \\
\text { length }\end{array}$ & 0.007798752807410 & 0.031189897 \\
\hline
\end{tabular}

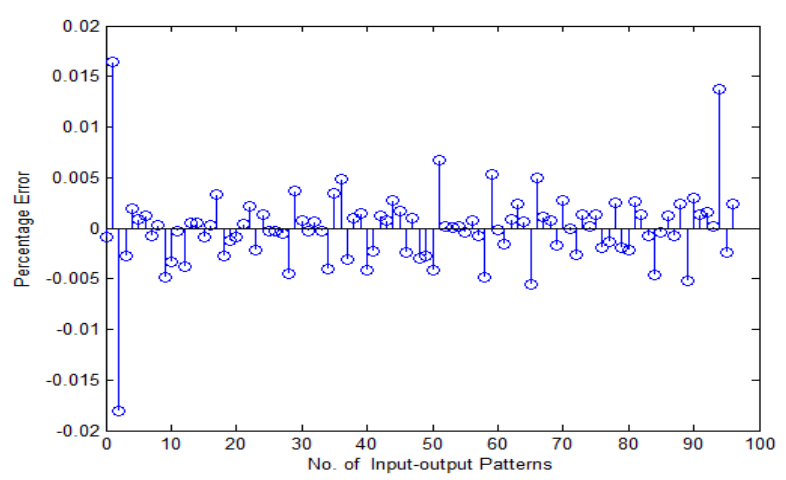

Fig.11 : Error (\% FS) between values of the side length of Sierpinski carpet fractal antenna obtained by simulation and estimated using ANN model as a result of training study.

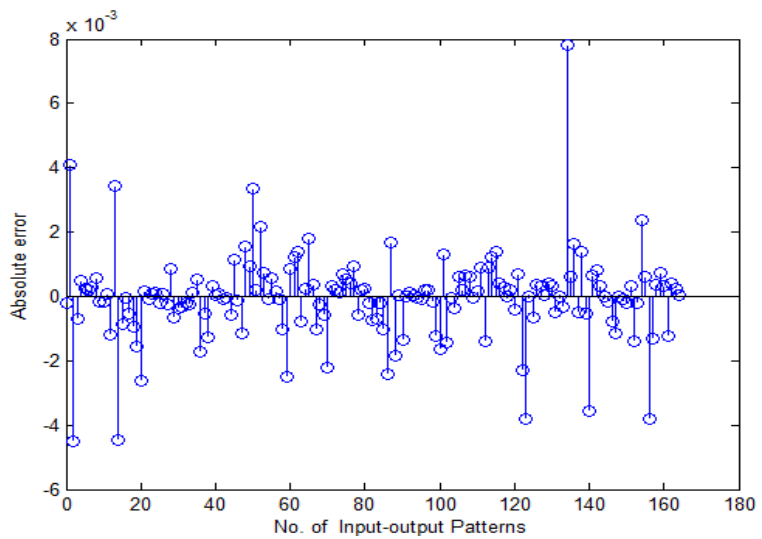

Fig.12: Absolute Error between values of the side length of Sierpinski carpet fractal antenna obtained by simulation and estimated by using ANN model as a result of validation study. trainıng aata

\begin{tabular}{|c|c|c|c|c|c|}
\hline Training & $\begin{array}{c}\text { Number } \\
\text { of neurons } \\
\text { in hidden } \\
\text { layer }\end{array}$ & $\begin{array}{c}\text { Epo } \\
\text { chs }\end{array}$ & MSE & $\begin{array}{c}\text { Absolut } \\
\text { e error }\end{array}$ & $\begin{array}{c}\text { \%age } \\
\text { error }\end{array}$ \\
\hline $\begin{array}{c}\text { Levenberg } \\
\text { Marquardt } \\
\text { algorithm }\end{array}$ & 35 & 177 & $\begin{array}{l}8.74 \mathrm{e}- \\
007\end{array}$ & 0.0045 & 0.0180 \\
\hline
\end{tabular}

Achievement of such low value of these errors (absolute and $\%$ FS) further authenticates that the ANN model is accurate model for the design of Sierpinski carpet fractal antenna.

\subsection{Results of Validation Study}

In order to validate the results for design of Sierpinski carpet fractal antenna, 165 inputs -output patterns are generated for testing proposed trained 4-35-1 ANN structure. The absolute error and error $(\% \mathrm{FS})$ at each value of side length of Sierpinski carpet fractal antenna as result of validation study for Levenberg Marquardt algorithm are shown in Table-2. Levenberg Marquardt training algorithm with Structure (4-351 ) is found best fit algorithm of ANN. The absolute error and error $(\% \mathrm{FS})$ at each value of side length of Sierpinski carpet 
fractal antenna as result of validation study are shown in Fig.12 and 13. It is observed that maximum absolute value of absolute error between side length of Sierpinski carpet fractal antenna after simulation and estimated from ANN as a result of validation study is found to be only 0.007798752807410 and that of error(\%FS) is 0.031189897869644

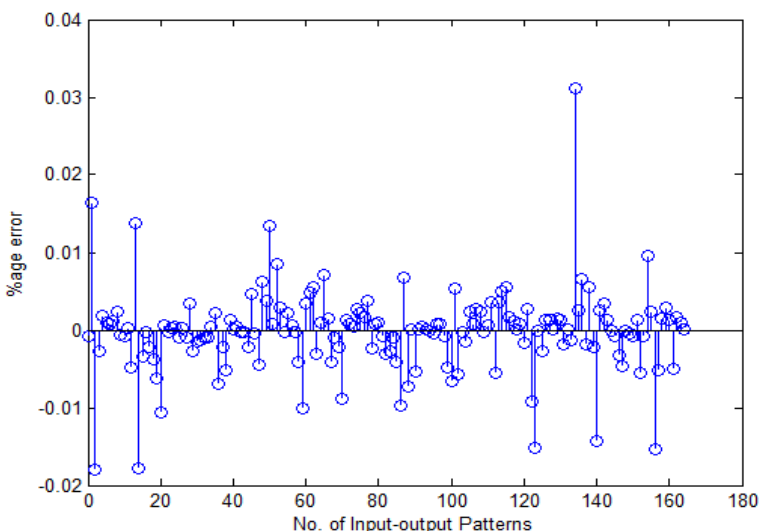

Fig.13: Error ( $\%$ FS) between values of the side length of Sierpinski carpet fractal antenna obtained by simulation and estimated by using ANN model as a result of validation study.

\section{CONCLUSION}

The present paper proposed an artificial neural network based simple approach for design of Sierpinski carpet fractal antenna. The proposed technique used multilayer feedforward back-propagation artificial neural network (MLFFBP-ANN) with one hidden layer as an approximate model for determining side length of antenna. The results of present study are quite promising. From the results, it is observed that the proposed modeling technique is very convenient to implement neural models for predicting the design parameters under specified conditions because an extremely small number of epochs are required to train the network with very large accuracy. Side length of Sierpinski carpet fractal antenna obtained by using ANNs is in very good agreement with simulated values as shown in Table-II. This close agreement supports the validity of proposed model.

\section{ACKNOWLEDGMENTS}

Authors are greatly indebted to the Department of Electronics and Communication Engineering, SLIET, Longowal-148106 (District: Sangrur), Punjab, India for providing excellent lab facilities that make this work feasible.

\section{REFERENCES}

[1] J.J. Haung, F.Q. Shan and J.Z. She, "A novel multiband and broad band fractal patch antenna," Progress in electromagnetic research symposium pp 57-59, March 2006.

[2] Cohen, "Fractal Antenna Applications in Wireless Telecommunications", IEEE Electronics Industries Forum of New England", Vol.12 pp 43-49, 1997.

[3] D. L. Jaggard, "On Fractal Electrodynamics", in H. N. Kritikos and D. L. Jaggard (eds.), Recent Advances in Electromagnetic theory, New York, Springer-Verlag, 1990, pp. 183- 224.
[4] D. Kalra, "Antenna Miniaturization Using Fractals," M.Sc. Thesis, University of Deemed, India, 2007

[5] Raida, Z, "Neural Networks in Antenna and Microwave," practical approach to radio engineering, Vol.10, no.4, pp24-35, 2001.

[6] S. Haykin, Neural Nehvorks: A Comprehensive Foundation, Englewood Cliffs, New Jersey, Macmillan Publishing Company, 1994.

[7] Cichocki and R. Unbehauen, "Neurul Networks for Optimization and Signal Processing," Chichester, England, J. Wiley \& Sons, 1994.

[8] J.L Narayan.., SriRama Krishna, K.Reddy, L.P, "Design of Microstrip Antenna Using Artificial Neural Networks," IEEE Trans, Vol. 1 pp 332-334, Dec 2007.

[9] M.Naseer-Moghaddasi, P.D. Barjeoi,A.Nagesh, "A heuristic Artificial Neural Network for Analyzing and synthesizing Rectangular Microstrip Antenna ,' IJCSNS, Vol 7,pp 278-281 Dec. 2007.

[10] R.K.Mishra and A.Pattnyak, "Designing rectangular patch antenna using the neurospectral method," IEEE Trans. Antennas Propagation .Vol 51, pp 1914-1921, Aug 2003.

[11] A.P.Singh and J Singh, "On the Design of A Rectangular Microsrip Antenna Using ANN,"National Journal of The Institution Of Engineers (India) Vol.29,pp 20-25July 2009.

[12] S. Sagiroglu,Kerim Guney,Mehmet Erler, "Computation of radiation efficiency for a resonant rectangular microstrip patch antenna using back propagation multilayered perceptrons,"Journal of Electerical \&Electronics,Vol 3,pp 663-671,Dec 2003.

[13] E.R. Brinhole, J.F.Z.Destro A.A.C de Feritas, "Determinations of Resonant Frequencies of Triangular and Rectangular Microstrip Antennas, Using Artificial Neural Networks," Electromagnetic Research Symposium Aug. 2005.

[14] Karaboga, D., K. G“uney, S. Sagiroglu and M. Erler, "Neural Computation of Resonant Frequency of Electrically Thin and Thick rectangular Microstrip Antennas," IEEE Proc. Microw. Antennas Proprag.,Vol. 146, 1999.

[15] S.Pattnaik,S.Panda,S.Devi;, "Input impedance of rectangular microstrip patch antenna using artificial neural networks," Revue/Journal Microwave and Optical Teach.Vol 32,pp 381-383,2002.

[16] S. A. Long and W. D. Walton, "A dual frequency stacked circular disc Antenna," IEEE Trans. Antenna and Propagation. AP, pp. 270-273, 1979.

[17] S.Pal Gangawar,B.K. Kanaujia ,Paras, "Resonant frequency of circular microstrip antenna using artificial neural networks," National Journal of Radio and Space Physics,Vol. 37,June 2008,pp.204-208, May 2008.

[18] S. Devi, D.C. Panda, S.S. Pattnaik, "A novel method of using artificial neural networks to calculate input impedance of circular microstrip antenna," Symposium Antennas and Propagation Society International, vol.3, pp. 462-465, 16-21 June 2002. 